Although the verdict must be 'indifferent' in Cooke terminology for the first edition, the second edition will undoubtedly be good if the editor realizes that it is already overdue and that it must be published soon.

\section{The Logic of Medicine}

By Edmond A. MURPhy. Pp. xi +353 , illustrated, hard cover. Baltimore and London: The Johns Hopkins University Press, 1976. $£ 11.55$.

This is a most unusual and interesting book and this reviewer believes it is difficult for anyone using measurement of any sort in medical practice to read it without profit. Its theme is the need for clarity of definition of the terms used in ordinary speech, writing (especially in scientific papers) and, further, for the processes of thought which go towards not only making a clinical diagnosis but assessments of treatment and of all the comparisons and judgments made in clinical medicine. It can be read by those without much knowledge of mathematics or statistics but it gains enormously in value if it is read in conjunction with a small text of statistics as applied to medicine: yet it must be emphasized that this is not necessary and it stands alone on its merits. Some idea of the range of this book can be given by quoting first 'The Objective' which states that 'The serious purpose of the book is to explore the ideas behind the evaluation of the sources and interpretation of the data from which the corpus of medical knowledge is to be derived'; and then some of the chapter headings such as 'Words, symbols, and notions'; 'Disease and normality'; 'The diagnostic process'; 'Superstition'; 'An exercise in qualitative criticism'. Running through the book is the wide scholarship and humour of the author.
The reviewer would particularly like medical students to re⿳亠口冋.9 it, but practising doctors would need to dispense with their bad or clumsy logical processes which may often be harmen to the patient. The book is well produced and is a credit to the Johns Hopkins University Press.

\section{A Synopsis of Physical Signs in Medicine}

By H. Fuld. Second edition. Pp. 218, soft cover. Londo $\frac{\Phi}{8:}$

K. K. Lewis \& Co Ltd., 1976. £5.00.

The diagnostic process depends on the gathering of infofmation from three sources, history, physical examination, and investigations. The former two yield up the diagnosis 9 a majority of cases and, as the author repeatedly stresses, careful clinical examination reduces the need for investigations which are often costly from several points of vieß, The book, however, does not concern itself solely wi physical signs, which cannot be sensibly treated in isolation. It also deals with symptoms, diseases and basic investigations such as the ECG and chest X-ray. There are some helpfun lists of 'causes', e.g. of hepatomegaly, purpura and the acupe abdomen, and some rather less helpful black and white reproductions of photographs of physical signs.

It is sad that students are still taught to analyse the radis rather than brachial pulse; the author also does not go into detail of how to measure blood pressure - a pity in view of the diagnostic importance placed on this single physical sign.

However, in spite of one or two errors and omissions, t㫘 book can be recommended to the medical student revising for his finals exam. 